\title{
Prescribing patterns of combined hormonal products containing cyproterone acetate, levonorgestrel and drospirenone in the UK
}

\author{
${ }^{1}$ Pharmacoepidemiologist, \\ Spanish Centre for \\ Pharmacoepidemiologic Research \\ (CEIFE), Madrid, Spain \\ ${ }^{2}$ Department of Preventive \\ Medicine and Public Health, \\ Faculty of Medicine, \\ Complutense University of \\ Madrid, Madrid, Spain \\ ${ }^{3}$ Professor, Department of Public \\ Health and Caring Science, \\ Uppsala University, Uppsala \\ Sweden
}

\section{Correspondence to} Dr Lucía Cea-Soriano, Pharmacoepidemiology, Spanish Centre for Pharmacoepidemiologic Research (CEIFE), Almirante 28, Madrid 28004, Spain luciaceife@gmail.com

Received 23 February 2015 Revised 2 March 2016 Accepted 16 March 2016 Published Online First 20 April 2016

\section{CLinked}

- http://dx.doi.org/10.1136/ jfprhc-2016-101585

\section{CrossMark}

$$
\begin{aligned}
& \text { To cite: Cea-Soriano L, } \\
& \text { Wallander M-A, García } \\
& \text { Rodríguez LA. J Fam Plann } \\
& \text { Reprod Health Care } \\
& \text { 2016;42:247-254. }
\end{aligned}
$$

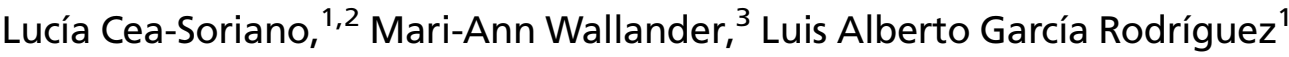
Aims To determine the diagnosis/indication recorded at the time of prescription of cyproterone acetate/ethinylestradiol (CPA/EE) and two COCs, levonorgestrel/EE (LNG/EE) and drospirenone/EE (DRSP/EE).

Design and setting Retrospective study using a primary care database, The Health Improvement Network (THIN).

Methods Women in THIN aged 12-49 years prescribed CPA/EE, LNG/EE or DRSP/EE in 20022010 were identified. Overall use of each product and proportion of new users each year were determined. Among new users, database codes were analysed to infer the reason for prescription. Results The proportion of new users of each product in 2002 and 2010, respectively, were: LNG/EE, $2.03 \%$ and $2.40 \%$; CPA/EE, $0.45 \%$ and $0.27 \%$; and DRSP/EE, $0.27 \%$ and $0.56 \%$. Most new users prescribed CPA/EE had a record of acne $(51.0 \%$ and $79.2 \%$ in 2002 and 2010 , respectively) or hirsutism (3.0\% and $5.0 \%$ in 2002 and 2010, respectively); the proportion of new users with a record only for contraception decreased from $32.9 \%$ in 2002 to $8.6 \%$ in 2010. Among new users prescribed DRSP/EE or LNG/EE in $2010,43.2 \%$ and $30.8 \%$ of women, respectively, did not have a record indicating use for contraception.

\section{Conclusions Adherence to prescribing} guidelines for CPA/EE has improved over time. A substantial proportion of women using DRSP/EE or LNG/EE had records for hormone-responsive conditions only, suggesting that many women were prescribed these therapies for noncontraceptive use.

\section{Key message points}

- There are limited data to show the levels of prescribing of estrogen/progestogen combinations that may be outside the approved product licence.

- In keeping with UK guidelines, the level of cyproterone acetate/ethinylestradiol (EE) prescribing for contraceptive use was low.

- The combined oral contraceptives levonorgestrel/EE and drospirenone/EE were commonly prescribed for reasons other than to provide contraception.

\section{INTRODUCTION}

In the 50 years since they were first introduced, combined oral contraceptives (COCs) have remained one of the most popular forms of contraception. In 2008/ 2009, a UK survey conducted by the Office of National Statistics reported that $25 \%$ of women aged $16-49$ years were using an oral contraceptive pill. ${ }^{1}$ In April-June 2010, 1.2 million prescriptions for COCs containing 30-40 $\mu \mathrm{g}$ ethinylestradiol (EE) were dispensed in England. ${ }^{2}$ It is well recognised that COCs may be prescribed for purposes other than contraception, but prescribing patterns for the non-contraceptive uses of COCs are poorly documented.

Studies have shown that some COCs can be effective in the treatment of acne. ${ }^{3}$ Some guidelines also recommend that these products can be used to manage menstrual disturbances such as dysmenorrhoea and menorrhagia, although the evidence for effectiveness in these 
conditions is based largely on observational studies. ${ }^{4-6}$ In fact, some formulations of COCs, such as levonorgestrel (LNG) and EE (LNG/EE), are also approved for the treatment of "recognised gynaecological indications for such oestrogen/progestogen combinations". ${ }^{7}$ In addition, women who do not require contraception may be prescribed hormonal contraceptives solely for these non-contraceptive purposes. ${ }^{8}$ The use of COCs for the treatment of hormone-responsive conditions such as acne or hirsutism, which could be outside the approved licences, may be common in clinical practice $;^{5-9}$ however, there are limited data to show how frequently COCs are prescribed for such use.

In the UK, the combination of cyproterone acetate $(\mathrm{CPA})$ and $\mathrm{EE}(\mathrm{CPA} / \mathrm{EE})$ is indicated for the treatment of moderate-to-severe acne related to androgen sensitivity (that has not responded to oral antibiotic therapy) and/or hirsutism in women of reproductive age. This combination is also an effective contraceptive, ${ }^{10}$ but marketing approval has not been sought for this indication. In many cases, acne and hirsutism occur as a result of elevated levels and/or increased action of circulating androgens, for example in polycystic ovary syndrome (PCOS); CPA/EE has the additional effect of helping to control the menstrual irregularities frequently associated with this condition. ${ }^{11}$ Recently, concerns have been raised in France regarding the risk of venous thromboembolism and the off-label use of CPA/EE as a contraceptive. ${ }^{12} \mathrm{~A}$ subsequent review by the European Medicines Agency found that the balance of benefits and risks of treatment with $\mathrm{CPA} / \mathrm{EE}$ remained positive, provided that several measures were taken to minimise the risk of thromboembolism, such as avoiding combination with other hormonal contraceptives. ${ }^{13}$

The aim of this study was to determine the diagnosis or indication recorded at the time of prescription of CPA/EE and two COCs, using data from a UK primary care database, The Health Improvement Network (THIN). We examined the patterns of use of $\mathrm{CPA} / \mathrm{EE}, \mathrm{LNG} / \mathrm{EE}$ and drospirenone (DRSP) and EE (DRSP/EE; first marketed in the UK in 2002 and only licensed for contraception). For each year of the study, we also determined the annual proportion of new users and the proportion of overall use (i.e. the total of new and existing users) among women aged 1249 years in THIN.

\section{METHODS}

\section{Study population}

THIN contains anonymised patient data recorded by general practitioners (GPs) in 578 participating primary care practices and includes approximately $6 \%$ of the UK population. ${ }^{14}$ In THIN, diagnoses are recorded using Read codes, and GPs can provide further information as free-text entries. ${ }^{15}$ To date, more than 380 research articles have been published using data from this source. ${ }^{14}$ The study population consisted of women in THIN aged 12-49 years between 1 January 2002 and 31 December 2010. To be eligible for inclusion in the study, women were also required to have been enrolled with their GP for at least 5 years and to have had a computerised prescription history of at least 1 year.

\section{Ascertainment of user groups}

To ascertain the number of women prescribed each treatment in each calendar year during the period 2002-2010 (inclusive), women who met the above criteria and who had been prescribed CPA/EE, LNG/ $\mathrm{EE}$ or DRSP/EE were identified. The date of first prescription during the study period was defined as the index date. $\mathrm{LNG} / \mathrm{EE}$ is available under several brand names, in which the dose of EE may be fixed (monophasic) or variable (phasic). All formulation types were included.

\section{Analysis of new and existing users}

Each user group was stratified according to previous prescription contraceptive use. New users were identified as having no record of using any of the study treatments before the year of interest, whereas existing users had records showing prescription of these products before the year of interest. New users of each treatment were further stratified into first-time (naïve) users and previous (non-naïve) users. Naïve users had no record of previous use of any hormonal contraceptive before the index date, whereas non-naïve users had previously received a hormonal contraceptive other than the study treatment.

For each new user, we identified diagnoses or indications relevant to the prescribing of these treatments during the earliest (2002) and most recent year (2010) of the study.

\section{Identification of the diagnosis or indication recorded at time of CPA/EE prescription}

We conducted computerised searches of the medical records of new CPA/EE users, whereby defined search terms were applied individually in a ranked order. Searches were restricted to the 90 days before and after the index date. $\mathrm{CPA} / \mathrm{EE}$ is approved for the treatment of acne (with or without seborrhoea) and/or hirsutism relating to androgen sensitivity in women of reproductive age. ${ }^{16}$ Most women presenting with symptoms of androgen excess have PCOS, ${ }^{17}$ which is also associated with alopecia, menstrual disturbances and anovulation. ${ }^{18}$ We therefore searched for Read codes suggestive of: (1) acne, including specific treatments such as tetracycline agents, macrolides, isotretinoin and topical treatments; (2) hirsutism; (3) PCOS; (4) oligomenorrhoea; (5) anovulation/infertility; (6) alopecia; and (7) gynaecological disorders. This final group included conditions such as dysmenorrhoea, menorrhagia, irregular menstruation, premenstrual 
syndrome, uterine fibroids, endometriosis and dyspareunia. For women who did not meet any of these criteria, we repeated these searches up to 1 year before the index date.

Cases for which no such diagnoses or specific treatments could be identified were analysed further for any information indicating use primarily for contraception. For the year before the index date, searches were conducted for Read codes indicating counselling on contraception or suggesting that a contraceptive had been prescribed. Finally, the computerised medical profiles of the remaining women were reviewed manually. Manual review was restricted to up to 1 year before and 90 days after the index date, prioritising the relevant entry closest to the index date. We looked for any code suggestive of conditions such as dysmenorrhoea, irregular menstrual bleeding, hirsutism or acne. Consecutive prescription of antibiotics was considered to indicate the coexistence of acne.

\section{Identification of the diagnosis or indication recorded at the time of DRSP/EE and LNG/EE prescriptions}

The computerised records of new DRSP/EE and LNG/EE users were searched for Read codes indicative of contraception and hormone-responsive conditions (acne, hirsutism, PCOS, infertility, alopecia, oligomenorrhoea and gynaecological disorders), using the methods described above for CPA/EE. Searches were restricted to the 90 days before and after the index date. Women who did not have a Read code indicating any of the above conditions were assumed to be using DRSP/EE or LNG/EE primarily for contraception.

\section{Analysis}

The proportion of overall use, as well as the proportion of new users of each product in every year of the study, were calculated and stratified by age. The statistical significance of the mean age at first prescription, comparing 2002 and 2010, was examined using a $t$-test for equal means (two-tailed). Analyses were performed using Stata ${ }^{\circledR}$ V.12.0 (StataCorp LP, College Station, TX, USA).

\section{RESULTS}

Baseline characteristics of new users

There were marked differences among the treatment groups in the distribution of naïve and non-naïve users (Table 1). The majority of LNG/EE users were naïve: $70.1 \%$ in 2002 and $74.3 \%$ in 2010 . In contrast, only $9.4 \%$ and $19.2 \%$ of DRSP/EE users were naïve to this treatment in 2002 and 2010, respectively. The status of CPA/EE users was more evenly distributed: $42.6 \%$ and $49.8 \%$ of women were naïve users in 2002 and 2010, respectively. For all groups, the mean ages of women when first prescribed these products were significantly lower in 2010 than in 2002 $(p<0.0001$; Table 1).
Annual proportion of new users and overall use of each product

The proportion of the study population who were new users of $\mathrm{CPA} / \mathrm{EE}$ was $0.45 \%$ in 2002 but declined to $0.27 \%$ by 2010 (Figure $1 \mathrm{~A}$ ). Over the period 2002-2010, the proportion of new users of LNG/EE and DRSP/EE increased from $2.14 \%$ to $2.40 \%$ and from $0.27 \%$ to $0.56 \%$, respectively. The overall use of LNG-EE decreased slightly, from $10.07 \%$ of the study population in 2002 to $8.68 \%$ in 2010 (Figure 1B). Overall CPA/EE use declined, with $1.61 \%$ of the study population being prescribed CPA/EE in 2002 compared with $0.95 \%$ in 2010 . The overall use of DRSP/EE increased from $0.27 \%$ of the study population in 2002, its first year of launch, to $1.87 \%$ in 2010. When stratified by age group, the rise and fall in the total use of CPA/EE mirrored the pattern observed in the overall user group (Figure 2A). There was a decrease in the proportion of women aged 1219 years and 30-39 years who were using LNG/EE (Figure 2B). The proportion of users of DRSP/EE increased in all age groups over the study period, but was most marked in those aged 20-29 years (Figure 2C).

\section{Recorded diagnosis or indication associated with the prescription of CPA/EE}

For new users of CPA/EE, manual review of medical records was required in $4.6 \%$ and $0.6 \%$ of cases in 2002 and 2010, respectively. Most women prescribed $\mathrm{CPA} / \mathrm{EE}$ had a recorded diagnosis of acne, and the proportion rose from $51.0 \%$ in 2002 to $79.2 \%$ in 2010 (Table 2). Most women had been prescribed acne treatment in the previous year: $78.8 \%$ and $71.8 \%$ in 2002 and 2010, respectively. The proportion of women with a record of using CPA/EE for the other approved indication, hirsutism, was only $3.0 \%$ in 2002 and 5.0\% in 2010. In 2002 and 2010, the proportion of women prescribed CPA/EE with a record of gynaecological disorders was $6.7 \%$ and $3.4 \%$, respectively. In 2002, almost one-third (32.9\%) of women prescribed CPA/EE had a record only for contraceptive use; this had decreased to $8.6 \%$ by 2010 .

\section{Recorded diagnosis or indication associated with the prescription of DRSP/EE or LNG/EE}

The proportion of women prescribed DRSP/EE who had a recorded diagnosis of acne increased from $11.8 \%$ in 2002 to $24.6 \%$ in 2010 (Table 2). In both years, the proportion of women with a record of gynaecological disorders at time of prescription was similar, at approximately $16 \%$.

For women who were prescribed LNG/EE, there was a record indicating gynaecological disorders for $14.5 \%$ of women in 2002 and for $20.3 \%$ of women in 2010. The proportion of women who had a related diagnosis of acne was $8.4 \%$ in 2002 and $9.0 \%$ in 2010. Less than $1 \%$ of women prescribed LNG/EE 
Table 1 Baseline characteristics of new users

\begin{tabular}{|c|c|c|c|c|c|c|c|c|c|c|c|c|c|c|c|}
\hline \multirow{4}{*}{ Characteristic } & \multicolumn{7}{|c|}{ Cyproterone acetate/ethinylestradiol } & \multicolumn{8}{|c|}{ Drospirenone/ethinylestradiol } \\
\hline & \multicolumn{3}{|l|}{2002} & \multicolumn{4}{|c|}{2010} & \multicolumn{4}{|c|}{2002} & \multicolumn{4}{|l|}{2010} \\
\hline & Naîve & \multicolumn{2}{|c|}{ Non-naiive } & \multicolumn{2}{|c|}{ Naîve } & \multicolumn{2}{|c|}{ Non-naïve } & \multicolumn{2}{|c|}{ Naiive } & \multicolumn{2}{|c|}{ Non-naïve } & \multicolumn{2}{|l|}{ Naîve } & \multicolumn{2}{|c|}{ Non-naïve } \\
\hline & $(42.6)$ & 916 & $(57.4)$ & 797 & $(49.8)$ & 802 & $(50.2)$ & 95 & (9.4) & 914 & $(90.6)$ & 649 & $(19.2)$ & 2724 & $(80.8)$ \\
\hline Mean age (years) (95\% Cl) & $20.7(20.2-21.3)$ & \multicolumn{2}{|c|}{$25.5(25.0-26.0)$} & \multicolumn{2}{|c|}{$18.2^{*}(17.8-18.6)$} & \multicolumn{2}{|c|}{$23.3^{*}(22.9-23.8)$} & \multicolumn{2}{|c|}{$23.4(21.7-25.2)$} & \multicolumn{2}{|c|}{$27.6(27.1-28.1)$} & \multicolumn{2}{|c|}{$18.7^{*}(18.3-19.2)$} & \multicolumn{2}{|c|}{$24.3^{*}(24.0-24.6)$} \\
\hline \multicolumn{16}{|l|}{ Age at prescription (years) } \\
\hline $12-19$ & $(66.3)$ & 236 & $(25.8)$ & 618 & (77.5) & 292 & (36.4) & 46 & $(48.4)$ & 155 & (17.0) & 498 & (76.7) & 894 & $(32.8)$ \\
\hline $20-29$ & (16.3) & 389 & $(42.5)$ & 137 & $(17.2)$ & 363 & $(45.3)$ & 23 & $(24.2)$ & 396 & $(43.3)$ & 111 & (17.1) & 1198 & $(44.0)$ \\
\hline $30-39$ & (14.1) & 262 & (28.6) & 33 & (4.1) & 127 & (15.8) & 22 & (23.2) & 300 & $(32.8)$ & 26 & $(4.0)$ & 521 & (19.1) \\
\hline $40-49$ & (3.2) & 29 & (3.2) & 9 & (1.1) & 20 & (2.5) & 4 & $(4.2)$ & 63 & (6.9) & 14 & $(2.2)$ & 111 & (4.1) \\
\hline
\end{tabular}

\begin{tabular}{|c|c|c|c|c|c|c|}
\hline \multirow[b]{2}{*}{ Characteristic } & \multicolumn{6}{|c|}{ Levonorgestrel/ethinylestradiol } \\
\hline & \multicolumn{2}{|l|}{2002} & \multicolumn{4}{|l|}{2010} \\
\hline & Naïve & Non-naïve & \multicolumn{2}{|l|}{ Naïve } & \multicolumn{2}{|c|}{ Non-naïve } \\
\hline & (70.1) & (29.9) & 7157 & $(74.3)$ & 2476 & (25.7) \\
\hline Mean age (years) $(95 \% \mathrm{Cl})$ & $20.7(20.4-20.9)$ & $27.3(27.0-27.7)$ & \multicolumn{2}{|c|}{$18.1^{*}(18.0-18.2)$} & \multicolumn{2}{|c|}{$24.9^{*}(24.5-25.2)$} \\
\hline \multicolumn{7}{|l|}{ Age at prescription (years) } \\
\hline $12-19$ & (66.3) & (22.8) & 5759 & (80.5) & 926 & (37.4) \\
\hline $20-29$ & (18.1) & (36.7) & 1028 & (14.4) & 816 & $(33.0)$ \\
\hline 30-39 & (11.7) & (32.1) & 261 & (3.6) & 552 & (22.3) \\
\hline 40-49 & (3.9) & (8.4) & 109 & (1.5) & 182 & (7.4) \\
\hline
\end{tabular}

${ }^{*} p<0.0001$ vs 2002.

Data are $n(\%)$ unless stated otherwise.

$\mathrm{Cl}$, confidence interval. 

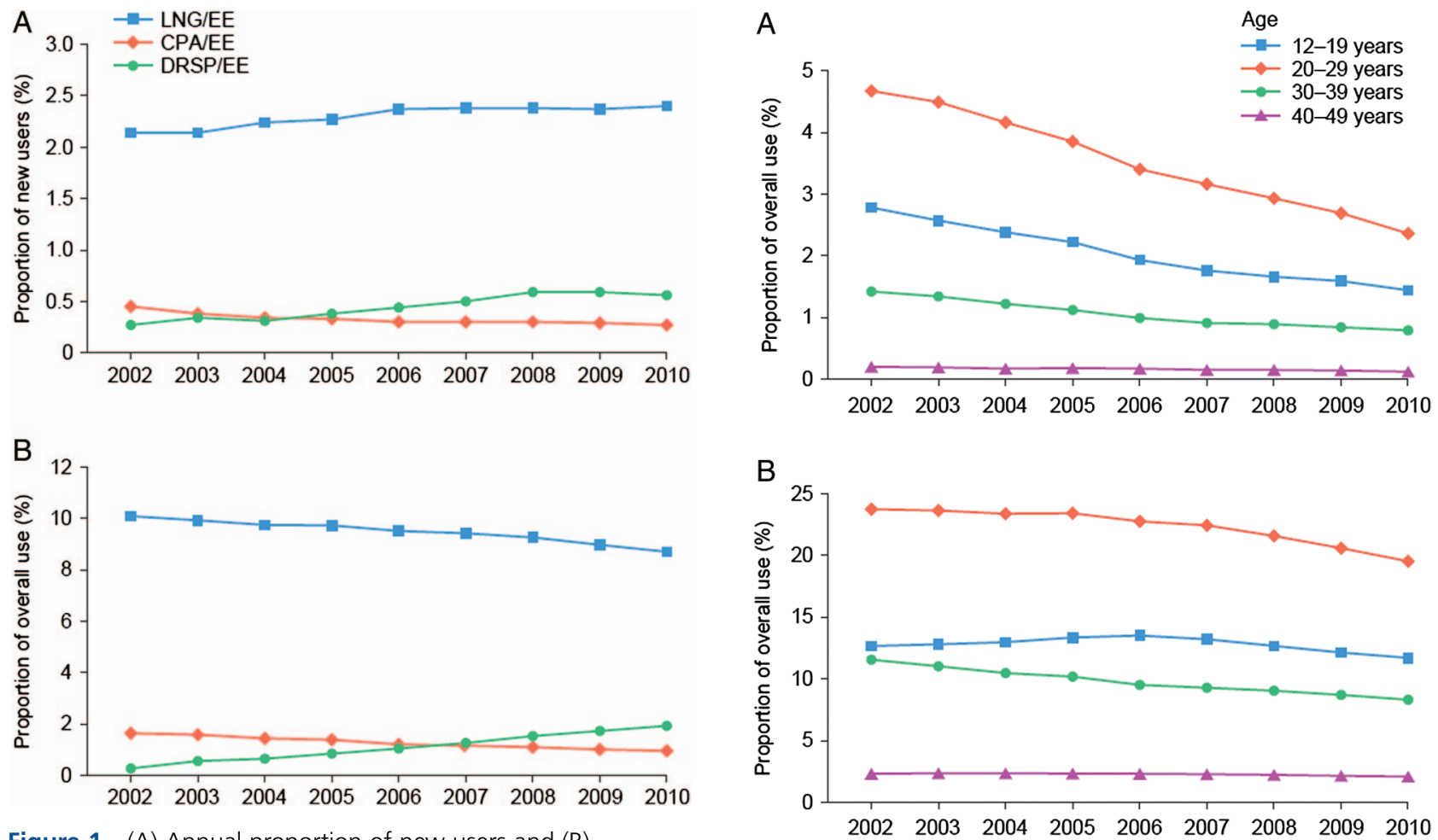

Figure 1 (A) Annual proportion of new users and (B) proportion of overall use of each product over the study period. CPA/EE, cyproterone acetate/ethinylestradiol; DRSP/EE, drospirenone/ethinylestradiol; LNG/EE, levonorgestrel/ ethinylestradiol.

had a concurrent record of any of the other conditions studied.

The proportion of women using DRSP/EE who had a recorded diagnosis of a hormone-responsive condition (as opposed to using DRSP/EE for contraception) rose from $30.4 \%$ in 2002 to $43.2 \%$ in 2010 . The corresponding change for users of $\mathrm{LNG} / \mathrm{EE}$ was from $24.3 \%$ to $30.8 \%$.

\section{DISCUSSION}

In our study there was a notable difference in the distribution of new users of LNG/EE and DRSP/EE. In 2010 , almost three-quarters $(74.3 \%)$ of women prescribed LNG/EE were first-time (naïve) users of COCs, whereas first-time users comprised $19.2 \%$ of those prescribed DRSP/EE. This difference may be explained by the UK guidelines on the first prescription of COCs, which recommend a monophasic formulation containing EE $(30 \mu \mathrm{g})$ and LNG or norethisterone. ${ }^{19}$ This guidance is based on the wellestablished safety profile and cost-effectiveness of LNG/EE preparations. ${ }^{20}$ For all groups, the mean age at first prescription was lower in 2010 than in 2002, which may suggest a trend towards women adopting COC use at an earlier age; however, further studies would be required to confirm this explanation. LNG/ EE remains the most commonly prescribed COC in the $\mathrm{UK}^{2}{ }^{2}$ although its use may have declined slightly over the study period. It is unclear whether this

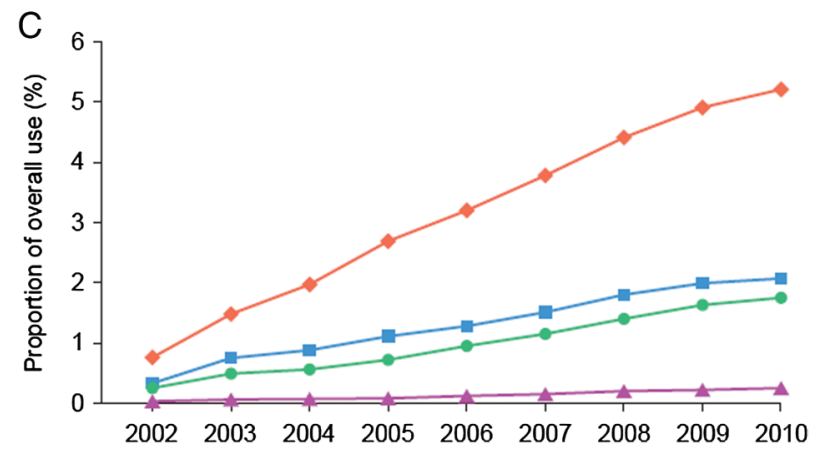

Figure 2 Proportion of overall use stratified by age over the study period for (A) cyproterone acetate/ethinylestradiol, (B) levonorgestrel/ethinylestradiol and (C) drospirenone/ ethinylestradiol.

decrease can be attributed to the introduction of new formulations of COCs, such as DRSP/EE. The results of our study suggest that, in 2010, approximately half the women using DRSP/EE and over two-thirds of the women using LNG/EE had been prescribed these COCs to provide contraception. In the most recent year of the study, most women using CPA/EE had a record suggesting use for the treatment of acne.

A strength of our study is the size of the population examined; we analysed the medical records of over 14000 women in 2010. Previous studies of this magnitude, for example the Oxford Family Planning Association study, ${ }^{21}$ have not specifically examined the prescribing of COCs for non-contraceptive use. We conducted searches of over 22000 anonymised medical records to identify the Read codes recorded at the time of prescribing, in order to infer the reason for 
Table 2 Diagnosis or indication associated with prescription of cyproterone acetate/ethinylestradiol and two combined oral contraceptives, as determined from medical records

\begin{tabular}{|c|c|c|c|c|c|c|}
\hline \multirow[b]{2}{*}{ Diagnosis/indication } & \multicolumn{2}{|c|}{$\begin{array}{l}\text { Cyproterone acetate/ } \\
\text { ethinylestradiol }\end{array}$} & \multicolumn{2}{|c|}{ Drospirenone/ethinylestradiol } & \multicolumn{2}{|c|}{ Levonorgestrel/ethinylestradiol } \\
\hline & $2002(n=1595)$ & $2010(n=1599)$ & $2002(n=1009)$ & $2010(n=3373)$ & $2002(n=5632)$ & $2010(n=9633)$ \\
\hline Acne & $813(51.0)$ & $1266(79.2)$ & $119(11.8)$ & $831(24.6)$ & 471 (8.4) & $868 \quad(9.0)$ \\
\hline Hirsutism & $48 \quad(3.0)$ & $80 \quad(5.0)$ & $2(0.2)$ & $16(0.5)$ & $2(0.04)$ & $9(0.1)$ \\
\hline Polycystic ovary syndrome & $70 \quad(4.4)$ & $46 \quad(2.9)$ & $7 \quad(0.7)$ & 38 (1.1) & $8(0.1)$ & $26 \quad(0.3)$ \\
\hline Oligomenorrhoea & $16(1.0)$ & $11(0.7)$ & $15(1.5)$ & $26 \quad(0.8)$ & $50 \quad(0.9)$ & $62(0.6)$ \\
\hline Infertility/anovulation & $1(0.1)$ & (0) & $(0)$ & $2(0.1)$ & $2(0.04)$ & $8(0.1)$ \\
\hline Alopecia & $15(0.9)$ & $4 \quad(0.3)$ & $4 \quad(0.4)$ & $13(0.4)$ & $18 \quad(0.3)$ & $34(0.4)$ \\
\hline Gynaecological disorders* & $107 \quad(6.7)$ & $55(3.4)$ & $160(15.9)$ & $531(15.7)$ & $815(14.5)$ & $1958(20.3)$ \\
\hline Contraception & $525(32.9)$ & 137 (8.6) & $702(69.6)$ & $1916(56.8)$ & $4266(75.7)$ & $6668(69.2)$ \\
\hline Read code for contraception & $472(89.9)$ & $130(94.9)$ & $643(91.6)$ & $1752(91.4)$ & $3711(87.0)$ & 6107 (91.6) \\
\hline No Read codet & $53(10.1)$ & $7 \quad(5.1)$ & $59(8.4)$ & 164 (8.6) & $555(13.0)$ & $561 \quad(8.4)$ \\
\hline
\end{tabular}

*Gynaecological disorders include dysmenorrhoea, menorrhagia, irregular menstruation, premenstrual syndrome, uterine fibroids, endometriosis and dyspareunia.

tIn the absence of a Read code indicating use for contraception or to treat hormone-responsive conditions, women were assumed to have been using the product for contraception.

prescribing. THIN has been validated for pharmacoepidemiological research and the results of this study are likely to be applicable to the UK population. ${ }^{22}$

However, our study also has limitations. As with all analyses using medical records, the reliability of the results is dependent on the quality and completeness of the recording of patient data. It is usual to assume that the contemporaneous recording of a diagnosis and the prescription of a relevant therapy are linked. For some users of $\mathrm{CPA} / \mathrm{EE}$ in our study, however, it was necessary to search up to a year before the index date to detect what was taken to be the underlying indication for the prescription. In such cases, it is possible that there was no causal link between the diagnosis found (e.g. of acne) and the prescription of CPA/ EE. Additionally, in a small proportion of women using $\mathrm{CPA} / \mathrm{EE}$, a relevant record could not be found. Approximately 1 in 10 women considered to be using DRSP/EE or LNG/EE for the intention of contraception did not have a related Read code.

To the best of our knowledge, this is the first study to assess the potential prescribing of $\mathrm{CPA} / \mathrm{EE}$ for contraceptive use and the prescribing of COCs for non-contraceptive use. A study by Tandy examined CPA/EE prescribing only, ${ }^{23}$ and a study by Seaman et al. ${ }^{24}$ published in 2003 focused on the use of CPA/ $\mathrm{EE}$ and COCs for the treatment of acne. In our study, a considerable proportion of women prescribed DRSP/EE or LNG/EE had medical conditions known to respond to COC therapy. In 2010, this applied to $43.2 \%$ of DRSP/EE users and $30.8 \%$ of LNG/EE users, and in some cases the indications were licensed. It should be noted that patients included in this study were of reproductive age and may have also required the provision of contraception. The incomplete recording of the main indication of COCs, to prevent unwanted pregnancy, cannot be excluded.
Studies investigating the proportion of prescribing that is off-label have reported estimates that range from $11 \%$ to $21 \% ;{ }^{25}{ }^{26}$ however, in these studies, most of such prescribing identified was judged to have had little or no scientific rationale. In contrast, the value of COC therapy is acknowledged in various clinical guidelines, including those for the treatment of androgen excess and/or PCOS, ${ }^{27}{ }^{28}$ heavy menstrual bleeding ${ }^{29}$ and endometriosis. ${ }^{30}$ Furthermore, COCs have good tolerability and very favourable cost-benefit ratios. Guidance concerning the prescribing of contraceptives outside the product license has been published. ${ }^{5}$ According to these guidelines, practitioners should discuss the evidence supporting this use and document this information in the case records. The results of our study suggest that a substantial number of women should be receiving such information. Furthermore, given that approximately $5-13 \%$ of patients had no Read code revealing the reason for prescribing, it is possible that many women may not have their case history adequately recorded.

The results from our study show that in 2002, $32.9 \%$ of women prescribed CPA/EE had only a record indicating contraceptive use, which decreased to $8.6 \%$ in 2010 . Given that our results are reliant on complete recording by GPs, it is likely that the true prescribing for contraceptive use alone is even lower than these data suggest. It is reassuring for patient welfare that CPA/EE appears to be used increasingly in accordance with prescribing guidelines. The apparent improvement in adherence to prescribing guidance may reflect the issuing of advice by UK regulators in 2002 and 2008 regarding the approved indications of $\mathrm{CPA} / \mathrm{EE}{ }^{31}{ }^{32}$ This guidance stated that CPA/EE should only be used within its licensed indication, should not be used solely for contraception, and use discontinued 3-4 months after resolution of symptoms. In a study 
of prescribing in one primary care practice in England, conducted in 2010 by Tandy, only 26 women were using CPA/EE, none of whom had been prescribed the treatment solely for contraception. ${ }^{23}$ Alternatively, the improvement in adherence to prescribing guidance may simply reflect an improvement in recording of this information in THIN over this time. When prescribed for the treatment of acne, CPA/EE should be used only after topical therapy or systemic antibiotic treatments have failed. ${ }^{16}$ In our study, approximately three-quarters of women prescribed CPA/EE with a concomitant diagnosis of acne also had a record of an alternative prescription for treatment of this condition in the previous year. Non-prescription medication is not captured in THIN, so it is likely that this is an underestimate of the proportion of women using acne treatment before commencing treatment with $\mathrm{CPA} / \mathrm{EE}$.

\section{CONCLUSIONS}

In 2010, most women using DRSP/EE and LNG/EE had medical records suggesting these treatments were prescribed to provide contraception; only a small proportion of women using CPA/EE had a record indicating use for this reason alone. These findings suggest that adherence to prescribing guidelines for $\mathrm{CPA} / \mathrm{EE}$ has improved over time. A substantial proportion of women using DRSP/EE and LNG/EE had a record only for medical conditions known to respond to COCs. However, incomplete recording of the intention to use DRSP/EE and LNG/EE for the most common purpose of any COC (to prevent unwanted pregnancy) cannot be excluded.

Acknowledgements Medical writing support, funded by Bayer Pharma AG, was provided by William Gattrell of Oxford PharmaGenesis Ltd.

Funding This study was funded by Bayer Pharma AG, Berlin, Germany.

Competing interests Lucía Cea-Soriano and Luis Alberto García Rodríguez are employees of CEIFE, which has received a research grant from Bayer Pharma AG for this work. Mari-Ann Wallander was an employee of AB Bayer, Solna, Sweden at the time of the study.

Ethics approval UK Multicentre Research Ethics Committee.

Provenance and peer review Not commissioned; externally peer reviewed.

\section{REFERENCES}

1 Office for National Statistics. Contraception and Sexual Health, 2008/09. http://www.ons.gov.uk/ons/rel/lifestyles/ contraception-and-sexual-health/2008-09/2008-09.pdf [accessed 7 December 2015].

2 NHS Business Services Authority. Contraceptives (September 2010). http://www.nhsbsa.nhs.uk/Documents/Jul_-_Sep_10_ Contraceptives.pdf [accessed 7 December 2015].

3 Arowojolu AO, Gallo MF, Lopez LM, et al. Combined oral contraceptive pills for treatment of acne. Cochrane Database Syst Rev 2009;3:CD004425.
4 ESHRE Capri Workshop Group. Noncontraceptive health benefits of combined oral contraception. Hum Reprod Update 2005;11:513-525.

5 Penney G, Brechin S, Allerton L. FFPRHC Guidance (July 2005): The use of contraception outside the terms of the product licence. J Fam Plann Reprod Health Care 2005;31:225-241.

6 Royal College of Obstetricians and Gynaecologists (RCOG). The Management of Menorrhagia in Secondary Care (Evidence Based Clinical Guidelines No. 5). London, UK: RCOG, 1999.

7 Microgynon ${ }^{\circledR}$ 30. Summary of Product Characteristics. 2014. http://www.medicines.org.uk/emc/medicine/1827/SPC/ Microgynon+30/ [accessed 7 December 2015].

8 Haider Z, D'Souza R. Non-contraceptive benefits and risks of contraception. Best Pract Res Clin Obstet Gynaecol 2009;23:249-262.

9 Huber JC, Bentz EK, Ott J, et al. Non-contraceptive benefits of oral contraceptives. Expert Opin Pharmacother 2008;9:2317-2325.

10 Aydinlik S, Kaufmann J, Lachnit-Fixson U, et al. Long-term therapy of signs of androgenisation with a low-dosed antiandrogen-oestrogen combination. Clinical Trials Journal 1990;27:392-402.

11 Franks S, Layton A, Glasier A. Cyproterone acetate/ethinyl estradiol for acne and hirsutism: time to revise prescribing policy. Hum Reprod 2008;23:231-232.

12 Collier R. Scrutiny of Diane-35 due to potential dangers of off-label prescribing. CMAJ 2013;185:E217-E218.

13 European Medicines Agency. Benefits of Diane 35 and its generics outweigh risks in certain patient groups. 2013. http:// www.ema.europa.eu/ema/index.jsp?curl=pages/medicines/ human/referrals/Cyproterone-_and_ethinylestradiol-containing_ medicines/human_referral_prac_000017.jsp\&mid= WC0b01ac05805c516f [accessed 7 December 2015].

14 CSD Medical Research UK. http://csdmruk.cegedim.com/ [accessed 7 December 2015].

15 Benson T. The history of the Read Codes: the inaugural James Read Memorial Lecture 2011. Inform Prim Care 2011;19:173-182.

16 Dianette ${ }^{\circledR}$. Summary of Product Characteristics. 2014. http:// www.medicines.org.uk/emc/medicine/1814/SPC/Dianette/ [accessed 7 December 2015].

17 Azziz R, Sanchez LA, Knochenhauer ES, et al. Androgen excess in women: experience with over 1000 consecutive patients. J Clin Endocrinol Metab 2004;89:453-462.

18 Sirmans SM, Pate KA. Epidemiology, diagnosis, and management of polycystic ovary syndrome. Clin Epidemiol 2013;6:1-13.

19 Faculty of Family Planning \& Reproductive Health Care. First Prescription of Combined Oral Contraception. 2007. http:// www.fsrh.org/pdfs/FirstPrescCombOralContJan06.pdf [accessed 7 December 2015].

20 NHS Wandsworth Clinical Commissioning Group. Quick reference guide for combined oral contraceptives. http://www. wandsworthccg.nhs.uk/aboutus/Prescribing\%20Guidelines/ Combined\%20Oral\%20Contraceptives\%20Update\%20-\% 202013\%20Final.pdf [accessed 7 December 2015].

21 Vessey MP, Lawless M. The Oxford-Family Planning Association contraceptive study. Clin Obstet Gynaecol 1984;11:743-757.

22 Blak B, Thompson M, Dattani H, et al. Generalisability of The Health Improvement Network (THIN) database: 
demographics, chronic disease prevalence and mortality rates. Inform Prim Care 2011;19:251-255.

23 Tandy RM. Co-cyprindiol prescribing in a large, rural general practice in England. J Fam Plann Reprod Health Care 2012;38:41-43.

24 Seaman HE, de Vries CS, Farmer RD. Differences in the use of combined oral contraceptives amongst women with and without acne. Hum Reprod 2003;18:515-521.

25 Eguale T, Buckeridge DL, Winslade NE, et al. Drug, patient, and physician characteristics associated with off-label prescribing in primary care. Arch Intern Med 2012;172:781-788.

26 Radley DC, Finkelstein SN, Stafford RS. Off-label prescribing among office-based physicians. Arch Intern Med 2006;166:1021-1026.

27 Martin KA, Chang RJ, Ehrmann DA, et al. Evaluation and treatment of hirsutism in premenopausal women: an endocrine society clinical practice guideline. J Clin Endocrinol Metab 2008;93:1105-1120.
28 Escobar-Morreale HF, Carmina E, Dewailly D, et al. Epidemiology, diagnosis and management of hirsutism: a consensus statement by the Androgen Excess and Polycystic Ovary Syndrome Society. Hum Reprod Update 2012;18:146-170.

29 National Collaborating Centre for Women's and Children's Health. Heavy Menstrual Bleeding. 2007. http://www.nice.org. uk/nicemedia/pdf/CG44NICEGuideline.pdf [accessed 7 December 2015].

30 Dunselman GA, Vermeulen N, Becker C, et al. ESHRE guideline: management of women with endometriosis. Hum Reprod 2014;29:400-412.

31 Committe on Safety of Medicines. Cyproterone acetate (Dianette): risk of venous thromboembolism (VTE). Current Problems in Pharmacovigilance 2002;28:9--10.

32 Medicines and Healthcare Products Regulatory Agency. Cyproterone acetate with ethinylestradiol (co-cyprindiol): recommended duration of use. Drug Safety Update 2008;1:4. 